\title{
MONOTONICITY RESULTS FOR THE POLYGAMMA FUNCTIONS
}

\author{
Ai-Jun Li, Jun YuAn AND ChaO-PING Chen
}

Abstract. In this paper, the monotonic results of the functions $x^{c}\left|\psi^{(n)}(x+\beta)\right|$ and $x \psi^{(n+1)}(x+$ $\beta) / \psi^{(n)}(x+\beta)$ are established. Several by-products are obtained. Moreover, we prove that the function $\frac{d \psi(\ln x)}{d x}$ is completely monotonic.

Mathematics subject classification (2000): 33B15, 26A48.

Key words and phrases: digamma function, polygamma functions, Laplace transforms, completely monotonic.

\section{REFERENCES}

[1] M. AbRAmowitZ AND I. A. STEgUn (EDS), Handbook of Mathematical Functions with Formulas, Graphs, and Mathematical Tables, National Bureau of Standards, Applied Mathematics Series 55, 4th printing, with corrections, Washington, 1965.

[2] H. AlzER, Some gamma function inequalities, Math. Comp. 60 (1993), 337-346.

[3] H. AlzER, On some inequalities for the gamma and psi functions, Math. Comput. 66 (1997) 373-389.

[4] H. Alzer, Mean-value inequalities for the polygamma functions, Aequationes Math. 61 (2001) 151-161.

[5] H. AlzER, Sharp inequalities for the digamma and polygamma functions, Forum Math., 16 (2004), $181-221$.

[6] H. Alzer AND O. G. RUEHR, A submultiplicative property of the psi function, J. Comput. Appl. Math., 101 (1999), 53-60.

[7] H. AlZeR AND S. RuscheweYh, A subadditive property of the gamma function, J. Math. Anal. Appl., 285 (2003), 564-577.

[8] H. Alzer AND J. Wells, Inequalities for the polygamma functions, SIAM J. Math. Anal. 29 (1998) $1459-1466$.

[9] K. BALL, Completely monotonic rational functions and Halls marriage theorem, J. Comb. Th., Ser. B, 61 (1994), pp. 118-124.

[10] C. Berg, J. P. R. Christensen, P. Ressel, Harmonic Analysis on Semigroups. Theory of Positive Definite and related Functions, Graduate Texts in Mathematics 100, Springer, Berlin-Heidelberg-New York, 1984.

[11] C. Berg, G. Forst, Potential Theory on Locally Compact Abelian Groups, Ergebnisse der Math., 87, Springer, Berlin, 1975.

[12] L. BONDESSON, Generalized Gamma Convolutions and related Classes of Distributions and Densities, Lecture Notes in Statistics 76, Springer, New York, 1992.

[13] W. A. DAY, On monotonicity of the relaxation functions of viscoelastic meterial, Proc. Cambridge Philos. Soc., 67 (1970), pp. 503-508.

[14] W. FelLeR, An Introduction to Probability Theory and its Applications, Vol. 2, Wiley, New York, 1966.

[15] C. L. FRENZEN, Error bounds for asymptotic expansions of the ratio of two gamma functions, SIAM J. Math. Anal., 18 (1987), no. 3, pp. 890-896.

[16] C. H. KimBERLING, A probabilistic interpretation of complete monotonicity, Aequat. Math., 10 (1974), pp. $152-164$.

[17] W. Magnus, F. OberhetTinger, And R. P. Soni, Formulas and Theorems for the Special Functions of Mathematical Physics, Springer, Berlin, 1966.

[18] M. MerkLe, Convexity, Schur-convexity and bounds for the gamma function involving the digamma function, Rocky Mountain J. Math. 28(3) (1998), 1053-1066. 
[19] B. Palumbo, Determinantal inequalities for the psi function, Math. Inequal. Appl. 2 (1999) 223-231.

[20] F. QI AND CH.-P. CHEN, A complete monotonicity property of the gamma function, J. Math. Anal. Appl., 296 (2004), no. 2, pp. 603-607.

[21] J. SÁNDOR, A Note on Certain Ineaualities for the Gamma Function, J. Ineq. Pure Appl. Math., 6(3) (2005), Art. 61. Available online at URL: http://jipam.vu.edu.au/

[22] L.-X. WANG ETC., Mathematical Handbook, People's Education Press, Beijing, China, 1979. (Chinese)

[23] ZH.-X. WANG AND D.-R. GuO, Tèshū Hánshù Gàilùn (Introduction to Special Function), The Series of Advanced Physics of Peking University, Peking University Press, Beijing, China, 2000. (Chinese)

[24] D. V. WIDDER, The Laplace Transform, Princeton Univ. Press, Princeton, NJ, 1941.

[25] J. WIMP, Sequence Transformations and their Applications, Academic Press, Nex York, 1981. 